\title{
Dentinal crack formation during root canal preparations by the twisted file adaptive, Reciproc and WaveOne instruments
}

\author{
Richard M. Gergi ${ }^{1}$, Nada E. Osta ${ }^{2}$, Alfred S. Naaman ${ }^{1}$
}

Correspondence: Dr. Richard M. Gergi

Email: drrichardgergi@hotmail.com
'Department of Endodontics, Faculty of Dentistry, Saint Joseph University, Beirut, Lebanon,

${ }^{2}$ Department of Prosthodontics, Faculty of Dentistry,

Saint Joseph University, Beirut, Lebanon

\section{ABSTRACT}

Objective: This study aimed to compare the frequency of dentinal microcracks after root canal shaping with 2 reciprocating (Reciproc and WaveOne) and 1 combined continuous reciprocating motion twisted files adaptive (TFA) rotary system. Materials and Methods: Ninety molars were chosen and divided into three groups of 30 each. Root canal preparation was achieved by using Reciproc R25, Primary WaveOne and TFA systems. All the roots were horizontally sectioned at 15, 9, and $3 \mathrm{~mm}$ from the apex. The slices were then viewed each under a microscope at $\times 25$ magnification to determine the presence of cracks. The absence/presence of cracks was recorded, and the data were analyzed with a Chi-square test. The significance level was set at $P<0.05$. Results: Instrumentation with Reciproc produced significantly more complete cracks than WaveOne and TFA $(P=0.032)$. The TFA system produced significantly less cracks then the Reciproc and WaveOne systems apically $(P=0.004)$. Conclusions: Within the limits of this study, the TFA system caused less cracks then the full reciprocating system (Reciproc and WaveOne). Single-file reciprocating files produced significantly more incomplete dentinal cracks than full-sequence adaptive rotary motion.

Key words: Adaptive motion, dentinal defects, microcracks, reciprocation, single-file system

\section{INTRODUCTION}

Instrumentation with nickel-titanium (NiTi) instruments can result in some complications such as root canal transportation, perforations and vertical root fracture. ${ }^{[1]}$ Shaping procedures can damage the root dentin, resulting in dentinal cracks which can develop into vertical root fractures. ${ }^{[2-4]}$ The most susceptible teeth to fracture are those with a narrow distomesial dimension compared with the linguobuccal diameter as in mesial roots of lower molars. ${ }^{[2]}$

With the newly introduced single-file NiTi systems Reciproc (VDW, Munich, Germany) and WaveOne (Dentsply Maillefer, Ballaigues, Switzerland) it is possible to shape canals with only 1 instrument, thereby requiring less time than rotary full-sequence systems. ${ }^{[5]}$ These files are produced with a special NiTi alloy (M-wire) subjected to a special thermal treatment process to increase the flexibility of the instrument. ${ }^{[6]}$ WaveOne and Reciproc files are used in a reciprocating motion, in order to reduce stress on the instrument and to minimize fracture of cyclic fatigue. ${ }^{[7,8]}$

Another new generation of NiTi instrumentation system has been introduced called the twisted files adaptive (TFA) (SybronEndo, Orange, CA). The TFA are produced by transforming the NiTi wire from the austenitic crystalline structure to the super-elastic crystalline R-phase structure by a method of heating and cooling. ${ }^{[9,10]}$ The TFA is used in a combination of both, reciprocating and continuous rotation. According to the

This is an open access article distributed under the terms of the Creative Commons Attribution-NonCommercial-ShareAlike 3.0 License, which allows others to remix, tweak, and build upon the work non-commercially, as long as the author is credited and the new creations are licensed under the identical terms.

For reprints contact: reprints@medknow.com

How to cite this article: Gergi RM, Osta NE, Naaman AS. Dentinal crack formation during root canal preparations by the twisted file adaptive, Reciproc and WaveOne instruments. Eur J Dent 2015;9:508-12.

DOI: $10.4103 / 1305-7456.172634$ 
load of pressure exerted on the file, the TFA instrument can change from continuous rotation to reciprocation mode with clockwise and counterclockwise angles varying from $0^{\circ}$ to $600^{\circ}$ up to $370-50^{\circ}$.

The quantity of dentine structure remnant is correlated to the strength of a root filled tooth. ${ }^{[1]}$ Dentine removal during root canal shaping was found to have an incidence on the formation of incomplete cracks. ${ }^{[12-14]}$ Moreover, it might be speculated that when using only one instrument, more stress will be generated during instrumentation, increasing the frequency of dentinal defects. ${ }^{[15]}$ Therefore, the aim of the present study was designed to evaluate the frequency of dentinal microcracks observed after root canal preparation with reciprocating (Reciproc and WaveOne) and "Adaptive Motion" (TFA) instruments. The null hypothesis was that there would be no significant differences in crack formation among groups.

\section{MATERIALS AND METHODS}

Ninety freshly extracted mandibular first and second molars with completely separated canals and mature apices were chosen. Only teeth with a curvature of the mesial root $<25^{\circ}$ were selected. ${ }^{[16]}$ Canals were controlled for apical patency with a size $15 \mathrm{~K}$-file (VDW). The canal width near the apex was approximately compatible with size 15 . This was checked with silver point sizes 15-25 (VDW). The coronal portions and distal roots of the teeth were removed by using a an Isomet low speed saw (Isomet; Buhler Ltd., Lake Bluff, NY) under water cooling, leaving mesial roots with approximately $18 \mathrm{~mm}$ in length to prevent the introduction of confounding variables. All roots were observed with under $\mathrm{a} \times 25$ magnification stereomicroscope (Expert DN; Müller Optronic, Erfurt, Germany) to exclude cracks. As a result, 120 teeth were selected.

Samples were randomly assigned to each group $(n=30)$ according to the system used for root canal shaping.

\section{Group 1: Reciproc group $(n=30)$}

All root canals were instrumented with the R25 (25/0.08) Reciproc single-file according to the instructions of the manufacturer. R25 was introduced with about amplitude of $3 \mathrm{~mm}$ with a slow in- and-out pecking motion and Reciproc VDW silver motor (VDW GmbH). After 3 pecking motions, the canal was irrigated with $\mathrm{NaOCl}(5.25 \%, 3 \mathrm{~mL})$. Root canal patency was verified with a size K15 file to the working length (WL). This procedure was repeated until R25 reached WL.
Group 2: WaveOne group $(n=30)$

WaveOne taper 0.08 and size 25 reciprocating file was introduced into the root canals in a slow in- and-out pecking motion with about amplitude of $3 \mathrm{~mm}$ according to the manufacturer's instructions. The WaveOne instrument was mounted on the VDW silver reciprocating motor using the manufacturer configuration setup. Root canals were irrigated with $\mathrm{NaOCl}(5.25 \%, 3 \mathrm{~mL})$ after 3 pecking motions.

\section{Group 3: Twisted files adaptive group $(n=30)$}

TFA instruments were used with the Elements Adaptive Motion Technology. Instrument sequence was TFA 25 taper 8 followed by TFA 25 taper 6 and 25 taper 4 to the WL. After reaching WL with 25 taper 4, TFA 25 taper 6 followed by TFA 25 taper 8 were taken to WL.

Between instruments, canals were irrigated with $\mathrm{NaOCl}(5.25 \%, 3 \mathrm{~mL})$.

\section{All groups}

After instrumentation, all root canals were irrigated with $\mathrm{NaOCl}(5.25 \%, 3 \mathrm{~mL})$. Irrigation was performed using an Endo-Eze (Ultradent, South Jordan, USA) irrigator tip mounted on a disposable $3 \mathrm{~mL}$ syringe. When preparation was achieved ethylenediaminetetraacetic acid $(15 \%, 1 \mathrm{~mL})$ (Wizard, Rehber Kimya San., Istanbul, Turkey) was applied for 1-min and canals were irrigated again with $\mathrm{NaOCl}(3 \mathrm{~mL})$. Each instrument was changed after 3 canals. The final apical preparation resulting was standardized to size 25 , taper $8 \%$ for all groups.

One operator performed all root canal preparations, and the assessments of the cross sections were performed by 2 examiners who were blinded in respect to all experimental groups.

After preparation, all the roots were sectioned horizontally at 3 (apical third), 9 (middle third) and 15 (cervical third) $\mathrm{mm}$ from the apex with a $0.1 \mathrm{~mm}$ low-speed saw (Leitz, Wetzlar, Germany) under water-cooling. To avoid any artifact by dehydration, the teeth were stored in purified filtered water throughout the experiment. ${ }^{[17,18]}$

\section{Dentinal microcrack evaluation}

All slices were observed under a digital stereomicroscope (Expert DN) at $\times 25$ magnification by using a cold light source and pictures were taken. In cases of discrepancy in the observations of the 2 examiners, the slices were inspected again and discussed until a consensus was reached. Fracture, 
incomplete cracks, and craze lines, as well as the relative and absolute length of the defects, were recorded by using the ImageJ software (National Institutes of Health, public domain). The incidences of the different defects were analyzed by using the Chi-square test and the Fisher exact test at a significance level of $P<0.05$. ${ }^{[18,19]}$

\section{Definitions of the defects}

No defect is root dentin without any lines or cracks on the external or the internal surface of root [Figure 1].

An incomplete crack is a line extending from the canal wall into the dentin without reaching the outer surface.

A complete crack is a line extending from the root canal wall to the outer surface of the root [Figure 2].

Craze lines are all other lines that did not reach any root surface or extend from the external surface into the dentin but did not attain canal wall.

\section{RESULTS}

The distribution of the different defects is summarized in Tables 1 and 2.

Overall, Reciproc produced significantly more complete cracks compared with WaveOne and TFA $(P=032)$. There was no significant difference between TFA and WaveOne $(P>0.05)$. Regarding the middle and coronal third sections (15 and $18 \mathrm{~mm}$ ), no significant difference was found between the 3 files systems $(P>0.05)$.

Only in the apical third section ( $3 \mathrm{~mm}$ ) Reciproc and WaveOne produced significantly more incomplete cracks than TFA $(P=0.004)$. In the middle third section $(9 \mathrm{~mm})$, only the Reciproc system produced significantly more incomplete cracks $(P=0.032)$. In the coronal third sections, no significant difference was found between the 3 file systems $(P>0.05)$.

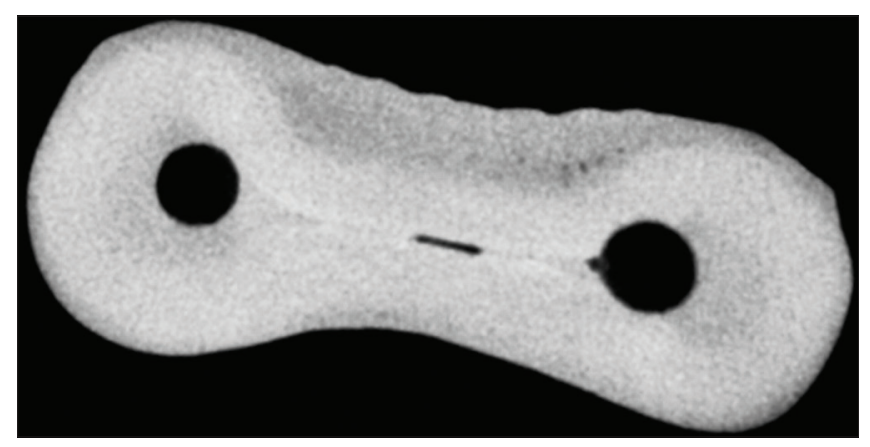

Figure 1: Cross section at the 3-mm without any dentinal defects
Craze lines were detected in the Reciproc group in the middle third with a significant difference $(P=0.003)$ [Table 3].

\section{DISCUSSION}

Vertical root fracture is not an instant phenomenon but rather a result of crack propagation. ${ }^{[20]}$ The main goal of the present investigation was to study the effect of two different kinematics using single-file and multiple file systems. This study revealed the incidence of dentinal defects was higher with single-file reciprocating instruments.

In the apical part of the canals, reciprocating files produced significantly more incomplete cracks compared with the rotary reciprocating adaptive motion $(P<0.05)$. The differences between the instruments tested regarding the incidence of dentinal defects may be due to the preparation technique and the cross-sectional design of instruments. The reciprocal motion seems to enhance debris transportation towards the apex and may increase torsional forces. ${ }^{[11,20]}$ It should be evaluated in further studies whether these increased torsional forces are associated with an increased risk of creating dentinal defects.

Reciproc instruments caused more complete cracks than WaveOne. The higher frequency may be correlated to the cross-sectional design of the instrument. In fact, the Reciproc R25 has an S-shaped geometry with a double cutting edge while WaveOne has a modified triangular cross section with radial lands at the tip and a convex triangular cross section in the middle and coronal portion of the instrument. The WaveOne cross section results in lower cutting efficiency and less chip space. ${ }^{[5,21]}$

In the apical third and in the whole root canal, TFA produced the least dentin defects. The lowest incidence may be due to the new adaptive reciprocating motion.

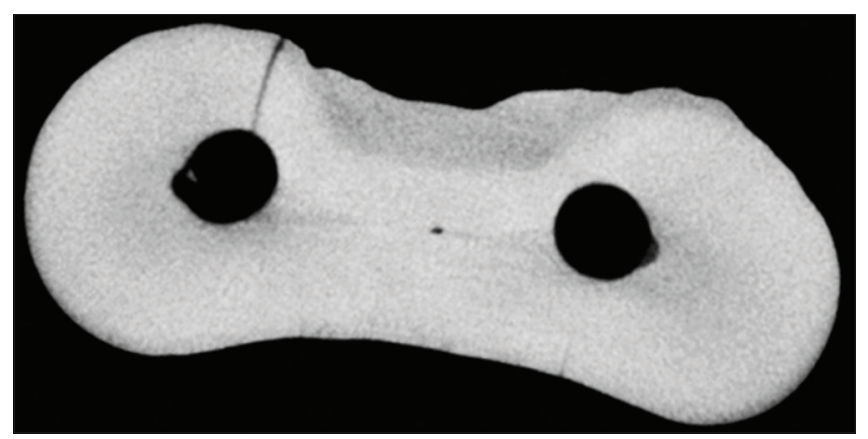

Figure 2: Cross section at the 3-mm level showing a complete crack 


\begin{tabular}{|c|c|c|c|c|}
\hline & \multicolumn{4}{|c|}{$\begin{array}{l}\text { Absolute number of complete cracks/ } \\
\text { percentage of specimens with complete } \\
\text { cracks }\end{array}$} \\
\hline & $\begin{array}{l}\text { Apical } \\
\text { third }\end{array}$ & $\begin{array}{c}\text { Middle } \\
\text { third }\end{array}$ & $\begin{array}{c}\text { Coronal } \\
\text { third }\end{array}$ & Total \\
\hline Reciproc $(n=30)$ & $4(13.3)^{a}$ & $0(0.0)$ & $0(0.0)$ & $\overline{4(4.4)^{a}}$ \\
\hline WaveOne $(n=30)$ & $0(0.0)^{\mathrm{b}}$ & $0(0.0)$ & $0(0.0)$ & $0(0.0)^{b}$ \\
\hline TFA $(n=30)$ & $0(0.0)^{\mathrm{b}}$ & $0(0.0)$ & $0(0.0)$ & $0(0.0)^{b}$ \\
\hline$P$ & 0.032 & 1.000 & 1.000 & 0.035 \\
\hline
\end{tabular}

Values with the same superscript letter were not statistically different, TFA: Twisted File Adaptive

\begin{tabular}{|c|c|c|c|c|}
\hline & \multicolumn{4}{|c|}{$\begin{array}{l}\text { Absolute number of incomplete cracks/ } \\
\text { percentage of specimens with incomplete } \\
\text { cracks }\end{array}$} \\
\hline & $\begin{array}{l}\text { Apical } \\
\text { third }\end{array}$ & $\begin{array}{l}\text { Middle } \\
\text { third }\end{array}$ & $\begin{array}{c}\text { Coronal } \\
\text { third }\end{array}$ & Total \\
\hline Reciproc $(n=30)$ & $12(40.0)^{a}$ & $4(13.3)^{a}$ & $0(0.0)$ & $16(17.8)^{a}$ \\
\hline WaveOne $(n=30)$ & $12(40.0)^{a}$ & $0(0.0)^{\mathrm{b}}$ & $0(0.0)$ & $12(13.3)^{a}$ \\
\hline TFA $(n=30)$ & $2(6.7)^{\mathrm{b}}$ & $0(0.0)^{b}$ & $0(0.0)$ & $2(2.2)^{b}$ \\
\hline$P$ & 0.004 & 0.032 & 1.000 & 0.003 \\
\hline
\end{tabular}

Values with the same superscript letter were not statistically different, TFA: Twisted File Adaptive

\begin{tabular}{|c|c|c|c|c|}
\hline & \multicolumn{4}{|c|}{$\begin{array}{c}\text { Absolute number of craze lines/ } \\
\text { percentage of specimens with craze } \\
\text { lines (\%) }\end{array}$} \\
\hline & $\begin{array}{l}\text { Apical } \\
\text { third }\end{array}$ & $\begin{array}{c}\text { Middle } \\
\text { third }\end{array}$ & $\begin{array}{c}\text { Coronal } \\
\text { third }\end{array}$ & Total \\
\hline Reciproc $(n=30)$ & $0(0.0)$ & $6(20.0)^{\mathrm{a}}$ & $0(0.0)$ & $6(6.7)^{\mathrm{a}}$ \\
\hline WaveOne $(n=30)$ & $0(0.0)$ & $0(0.0)^{b}$ & $0(0.0)$ & $0(0.0)^{b}$ \\
\hline TFA $(n=30)$ & $0(0.0)$ & $0(0.0)^{b}$ & $0(0.0)$ & $0(0.0)^{b}$ \\
\hline$P$ & 1.000 & 0.003 & 1.000 & 0.004 \\
\hline
\end{tabular}

The file uses continuous rotation when it is exposed to a minimal or no applied load and uses reciprocal motion when it engages dentin and load is applied..$^{[22]}$ The adaptive motion combined with the high flexibility and the multi-file system seems to decrease torsional forces resulting in less dentine defects.

No definitive conclusion can be made regarding the clinical implication of these dentinal defects on long-term follow-up. The presence of microcracks and dentinal defects after instrumentation has been reported. ${ }^{[2,23]}$ These dentinal defects can become high-stress concentration areas which may propagate to the root canal surface when an external force is applied. ${ }^{[24]}$ Currently, there is an evident lack of correlation between the results obtained in this type of studies and the clinical situation. Despite efforts to reproduce the clinical conditions, it is impossible to eliminate possible influence of external factors such as storage of the specimens.

The sectioning method used in the study allowed evaluation of the impact of root canal treatment procedures on dentin root by direct inspection of the root. This method is in agreement with a methodology described in a previous study. ${ }^{[17,25]}$ However, other methods have been described such as stress distribution measures, observations of the presence of cracks in tooth sections, and resistance of the root canal treated tooth to fracture. ${ }^{[24,26-28]}$ The latter method applies an external force until root fractures. ${ }^{[28]}$ The method in the present study differed from that approach because no external forces were applied, and the influence of root canal preparation on the root canal walls and the adjacent dentin was observed directly. In addition, resistance to fracture does only provide information on vertical root fracture, but the occurrence of dentinal defects cannot be detected.

\section{CONCLUSIONS}

Under the study limitations, there was a significant difference between the groups in the formation of dentinal microcracks. Therefore, the null hypothesis is rejected. The TFA system caused less root microcracks than the Reciproc and WaveOne files. Overall, Reciproc produced the most complete microcracks. Further studies are required to assess the advantage of single-file reciprocating root canal instrumentation concerning its impact on the incidence of root microcracks.

\section{Financial support and sponsorship}

Nil.

\section{Conflicts of interest}

There are no conflicts of interest.

\section{REFERENCES}

1. Tamse A, Fuss Z, Lustig J, Kaplavi J. An evaluation of endodontically treated vertically fractured teeth. J Endod 1999;25:506-8.

2. Bier CA, Shemesh H, Tanomaru-Filho M, Wesselink PR, Wu MK The ability of different nickel-titanium rotary instruments to induce dentinal damage during canal preparation. J Endod 2009;35:236-8.

3. Shemesh H, Roeleveld AC, Wesselink PR, Wu MK. Damage to root 
dentin during retreatment procedures. J Endod 2011;37:63-6.

4. Abou El Nasr HM, Abd El Kader KG. Dentinal damage and fracture resistance of oval roots prepared with single-file systems using different kinematics. J Endod 2014;40:849-51.

5. You SY, Kim HC, Bae KS, Baek SH, Kum KY, Lee W. Shaping ability of reciprocating motion in curved root canals: A comparative study with micro-computed tomography. J Endod 2011;37:1296-300.

6. Berutti E, Chiandussi G, Paolino DS, Scotti N, Cantatore G, Castellucci A, et al. Canal shaping with WaveOne Primary reciprocating files and ProTaper system: A comparative study. J Endod 2012;38:505-9.

7. De-Deus G, Leal Vieira VT, Nogueira da Silva EJ, Lopes H, Elias CN, Moreira EJ. Bending resistance and dynamic and static cyclic fatigue life of Reciproc and WaveOne large instruments. J Endod 2014;40:575-9.

8. Carvalho Mde S, Junior EC, Bitencourt Garrido AD, Roberti Garcia Lda F, Franco Marques AA. Histological evaluation of the cleaning effectiveness of two reciprocating single-file systems in severely curved root canals: Reciproc versus WaveOne. Eur J Dent 2015;9:80-6.

9. Gergi R, Rjeily JA, Sader J, Naaman A. Comparison of canal transportation and centering ability of twisted files, Pathfile-ProTaper system, and stainless steel hand K-files by using computed tomography. J Endod 2010;36:904-7.

10. Gambarini G, Gergi R, Naaman A, Osta N, Al Sudani D. Cyclic fatigue analysis of twisted file rotary NiTi instruments used in reciprocating motion. Int Endod J 2012;45:802-6.

11. Adorno CG, Yoshioka T, Jindan P, Kobayashi C, Suda H. The effect of endodontic procedures on apical crack initiation and propagation ex vivo. Int Endod J 2013;46:763-8.

12. Adorno CG, Yoshioka T, Suda H. The effect of working length and root canal preparation technique on crack development in the apical root canal wall. Int Endod J 2010;43:321-7.

13. Adorno CG, Yoshioka T, Suda H. Crack initiation on the apical root surface caused by three different nickel-titanium rotary files at different working lengths. J Endod 2011;37:522-5.

14. Bürklein S, Tsotsis P, Schäfer E. Incidence of dentinal defects after root canal preparation: Reciprocating versus rotary instrumentation. J Endod 2013;39:501-4.

15. Liu R, Hou BX, Wesselink PR, Wu MK, Shemesh H. The incidence of root microcracks caused by 3 different single-file systems versus the ProTaper system. J Endod 2013;39:1054-6.

16. Schneider SW. A comparison of canal preparations in straight and curved root canals. Oral Surg Oral Med Oral Pathol 1971;32:271-5.

17. Karatas E, Arslan H, Alsancak M, Kirici DÖ, Ersoy I. Incidence of Dentinal Cracks after Root Canal Preparation with Twisted
File Adaptive Instruments Using Different Kinematics. J Endod 2015;41:1130-3.

18. Kansal R, Rajput A, Talwar S, Roongta R, Verma M. Assessment of dentinal damage during canal preparation using reciprocating and rotary files. J Endod 2014;40:1443-6.

19. Karatas E, Gündüz HA, Kirici DÖ, Arslan H, Topçu MÇ, Yeter KY. Dentinal crack formation during root canal preparations by the twisted file adaptive, ProTaper Next, ProTaper Universal, and WaveOne instruments. J Endod 2015;41:261-4.

20. Bürklein S, Tsotsis P, Schäfer E. Incidence of dentinal defects after root canal preparation: Reciprocating versus rotary instrumentation. J Endod 2013;39:501-4.

21. Topcu KM, Karatas E, Ozsu D, Ersoy I. Efficiency of the Self Adjusting File, WaveOne, Reciproc, ProTaper and hand files in root canal debridement. Eur J Dent 2014;8:326-9.

22. Capar ID, Ertas H, Ok E, Arslan H, Ertas ET. Comparative study of different novel nickel-titanium rotary systems for root canal preparation in severely curved root canals. J Endod 2014;40:852-6.

23. Lam PP, Palamara JE, Messer HH. Fracture strength of tooth roots following canal preparation by hand and rotary instrumentation. J Endod 2005;31:529-32.

24. Lertchirakarn V, Palamara JE, Messer HH. Load and strain during lateral condensation and vertical root fracture. J Endod 1999;25:99-104.

25. Ustun Y, Aslan T, Sagsen B, Kesim B. The effects of different nickel-titanium instruments on dentinal microcrack formations during root canal preparation. Eur J Dent 2015;9:41-6.

26. Obermayr G, Walton RE, Leary JM, Krell KV. Vertical root fracture and relative deformation during obturation and post cementation. J Prosthet Dent 1991;66:181-7.

27. Saw LH, Messer HH. Root strains associated with different obturation techniques. J Endod 1995;21:314-20.

28. Ribeiro FC, Souza-Gabriel AE, Marchesan MA, Alfredo E, Silva-Sousa YT, Sousa-Neto MD. Influence of different endodontic filling materials on root fracture susceptibility. J Dent 2008;36:69-73.

\begin{tabular}{|l|l|}
\hline \multicolumn{2}{|c|}{ Access this article online } \\
\hline Quick Response Code: \\
\hline
\end{tabular}

